\title{
Metaheuristic Optimization of External Shading Devices and Glazing Properties for Energy Saving and Indoor Environmental Comfort in Office Rooms
}

\author{
Lorenzo De Donatis ${ }^{1}$, Ryozo Ooka ${ }^{2}$, Claudio Del Pero ${ }^{3}$, Wonjun Choi $^{2}$, Fabrizio Leonforte ${ }^{3}$, \\ Shintaro Ikeda ${ }^{4}$ \\ ${ }^{1}$ AUIC Dep, Politecnico di Milano, Milan, Italy \\ ${ }^{2}$ IIS, The University of Tokyo, Tokyo, Japan \\ ${ }^{3}$ ABC Dep, Politecnico di Milano, Milan, Italy \\ ${ }^{4}$ Tokyo University of Science, Tokyo, Japan
}

\begin{abstract}
The present work aims to analyse the application of a metaheuristic optimization approach to the design process of external shading devices and to assess the obtainable energy performance and comfort conditions; a full search optimization and a nature-inspired metaheuristic search have been compared to a traditional design approach. Subsequently, the analysis has been extended to the optimization of glazing properties in order to estimate the advantage in terms of simulation time for such process when the number of variables increases. Further considerations on the possibility to improve the optimization by acting on the Particle Swarm Optimization (PSO) parameters are also included in the study, providing a possible mutation of the traditional swarm movement. Developed methods have been applied to a real case-study office building.
\end{abstract}

\section{Introduction}

The building sector is highly affecting the world's energy use, covering in Europe almost $40 \%$ of the total energy consumption and having a huge impact on $\mathrm{CO}_{2}$ emissions (EU Hub, 2016). In such framework, it is pivotal, during a building design or renovation phase, to focus on the new requirements related to Nearly Zero Energy Buildings (NZEB) standards, according to the Energy Performance of Building Directive (EPBD). The use of shading devices is pivotal in commercial buildings to reach high energy saving and is often imposed by regulations (Decreto del Presidente della Repubblica, 2009). Thus, it is important to optimize them in order to reduce summer overheating while maximising solar gains during winter and decreasing glare problems during the whole year (Aste, 2012). The potential yearly energy saving due to external shadings varies according to the local climate, ranging from a minimum of $1 \%$ in cold climates up to over $20 \%$ in hotter ones (Bellia, 2013).

The importance of reducing solar gains in hot climates brought to the development of many rules of thumb and conventional practices in the design of shading devices, such as the orientation of the building main side towards North/South axis (Morrissey, 2011), the use of vertical fins or louvres on the East/West façades and so on. Conventional rules, however, might bring to non-optimal or even bad results when applied without consciousness of the specific application context in which they are adopted. Besides, when simulating the behaviour of a certain solution, it is fundamental to examine all the different parameters that influence the final performance; shading a building does not only mean reducing direct solar radiation entering the room, but also reduces the useful contribute of daylighting, which can be a big disadvantage for visual comfort of occupants as well as for the costs related to the need of artificial lighting (Grynning, 2014). As a matter of fact, the optimization of shading devices needs to consider several factors including climate, building geometry, construction typology and even users' needs. Such process also requires assessing heating, cooling and lighting energy demands and also computing eventual visual discomfort (Yener, 1998), which makes of it a complex study.

In such respect, the present research proposes a metaheuristic optimization methodology for fixed shading devices, with the aim of speeding up the design process. The method has been tested on the sizing of vertical fins applied to a real case-study building.

\section{Methodology}

Three different methods have been compared for the optimization of vertical shading devices (and then extended to glazing properties) as follows.

1) Traditional approach: this process follows a linear procedure, the steps of which are usually driven by the designer's experience and traditional rules of thumb (Reinhart, 2010) for daylight predictions. This is a fast method but often the identified solution is not the real optimal one.

2) Full search approach: this process considers and simulates all the possible design alternatives, guaranteeing the optimality of the final solution, but requires a significantly high computation load.

3) Metaheuristic algorithm (Yang, 2010): this approach typically leads to results which are much more accurate than the traditional approach with a sensibly lower computation load compared to the full search.

The reliability of metaheuristic algorithms, characterized by a particle swarm optimization (PSO), has already been proved in many research fields (Chantrelle, 2011); the present work aims to show how it can be used in the optimization of passive solar strategies (i.e. fixed shading devices and glazing proprieties), with the goal of reaching very good results in terms of energy saving and visual comfort, ensuring a healthy and productive environment for workers (Vischel, 2011) with competitive simulation times. 
In the present study, the parameters that need to be optimized are the geometrical features of the shading device, i.e. the depth $d$ and orientation angle $\beta$ (relative to the window pane) of the vertical fins, as shown in Figure 1.

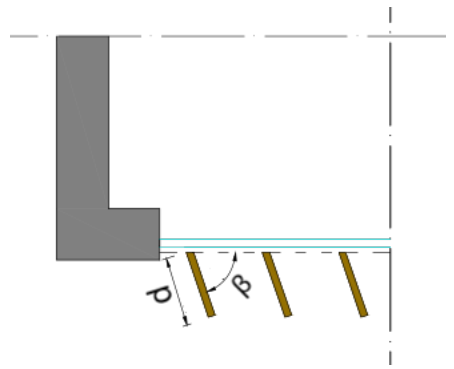

Figure 1: Vertical fins' geometric properties.

The following sub-sections outline the main features, pros and cons of the three adopted approaches.

\section{Traditional approach}

This method is based on a linear path, focusing on a single parameter, finding its best configuration and then passing to the next one. The experience of the designer is fundamental in finding an optimized final result, which might not always be the best solution due to the linearity of the process and the use of universal design rules (Mohsini, 2006). In this specific case the first parameter that was optimized is the depth of the selected shading device and, once fixed, the tilt angle of the latter has been considered, with the aim of decreasing energy consumption and ensuring that cDA (continuous daylight autonomy) and $\mathrm{G}$ (glare) parameters are within comfortable limits. Glare constraint is set up to be met only if less than $10 \%$ of yearly working hours are above the pre-set discomfort glare index (DGI); it is computed by EnergyPlus simulation tool through a complex formula which includes geometric parameters such as solid angle and position index for the determination of the luminance values perceived by the users. In order to evaluate discomfort of users due to a too high level of illuminance, a glare set point of 28 DGI has been set (Carlucci, 2015), as it could be considered the maximum bearable value for users (Aste, 2018). Daylight constraint, instead, is only satisfied when the cDA reaches a minimum value of $65 \%$ during yearly working hours (Chan, 2013). Only solutions meeting these criteria are considered among the possible design alternatives.

However, the final combination of depth and orientation angle might not ensure the best results in terms of energy saving and comfort, due to design choices. For instance, if the angle would have been fixed first, a different solution would have been reached; this means that one of the two options would have been worse than the other, or in other terms, could have been considered as a "local optimum". Consequently, this method can reach approximately-good solutions only in case of simple problems, characterized by a low number of variables and typically leads to a final choice that could be far from the truly best design option.

\section{Full search}

The full search approach is characterized by a simultaneous study of the design parameters, analysing all their possible combinations within a pre-selected range. The accuracy of the solution is usually guaranteed but, if seeking for high accuracy in a complex problem, a very high simulation time might be required, which represents the drawback of this method (Yang, 2010). The absence of a middleware software which includes the possibility of modifying properties of the model without the need of doing it manually, such as Building Control Virtual Test Bed - BCVTB (Wetter, 2011), which is instead widely used for the real-time control of energy management and control systems, brought us to code a script in Matlab; this is able to modify the properties of the shading devices covering all the hundreds of possible combinations and then run an equal number of simulations of EnergyPlus, while plotting results on a final Pareto diagram, which summarizes the whole search (Figure 2). Avoiding the use of a third-party tool and thus directly connecting Matlab and EnergyPlus allows to manage any kind of variable and to set constraints that can be adapted to any situation.

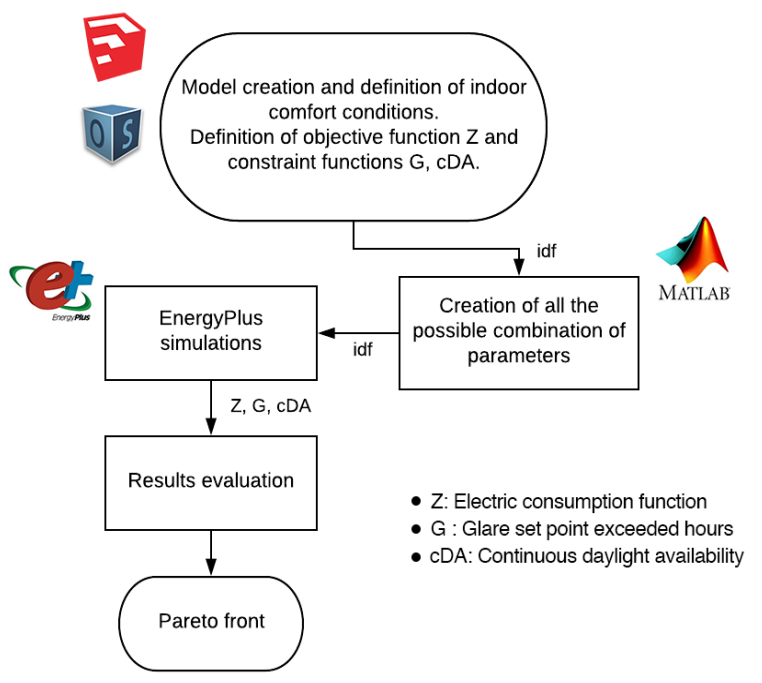

Figure 2: Full search approach's workflow.

While ' $Z$ ' represents the objective function to be minimized (yearly electric consumption for heating, cooling and lighting), functions $\mathrm{G}$ (glare) and cDA (continuous daylight autonomy) are responsible of the exclusion of those results which do not satisfy imposed constraints.

\section{Particle swarm optimization}

This approach is similar to the previous one in the sense that the whole search space is studied, but with the difference that the PSO will only evaluate the outcomes of a certain number of possible solutions, reaching a nearly-optimal result without the need of performing an excessive number of simulations; thus, it's especially useful when dealing with contradictory parameters (Znouda, 2007).

The accuracy of the result depends on the PSO parameters and the population's number (Trelea, 2003), which will 
be analysed in detail later on. The value of the inertia function and learning parameters within the PSO have been chosen according to previous studies which demonstrated convergent trajectories (Van Den Bergh, 2005). The work-flow for this method is similar to that of the full search approach, with the only difference that a part of code has been added in order to have a feedback from EnergyPlus to Matlab on the results of each particle (after each iteration), in such a way that the next movement of that particle will depend on current results. An end-criterion has also been added to the code to evaluate whether stopping the optimization or going on with the following iteration (Figure 3). Functions Z, G and cDA are treated in a similar way as described in the full search approach. In this method, however, functions $G$ and cDA are responsible of assigning, through a penalty method, higher values to the objective functions of out of constraint particles to avoid that they could consider the current position as a personal or global best, which might lead to wrong conclusions (Banks, 2008). Those functions assign a penalty value whenever the relative constraint is not satisfied, as set in the traditional approach. This ends up in the exclusion of those solutions from the list of possible optimal results.

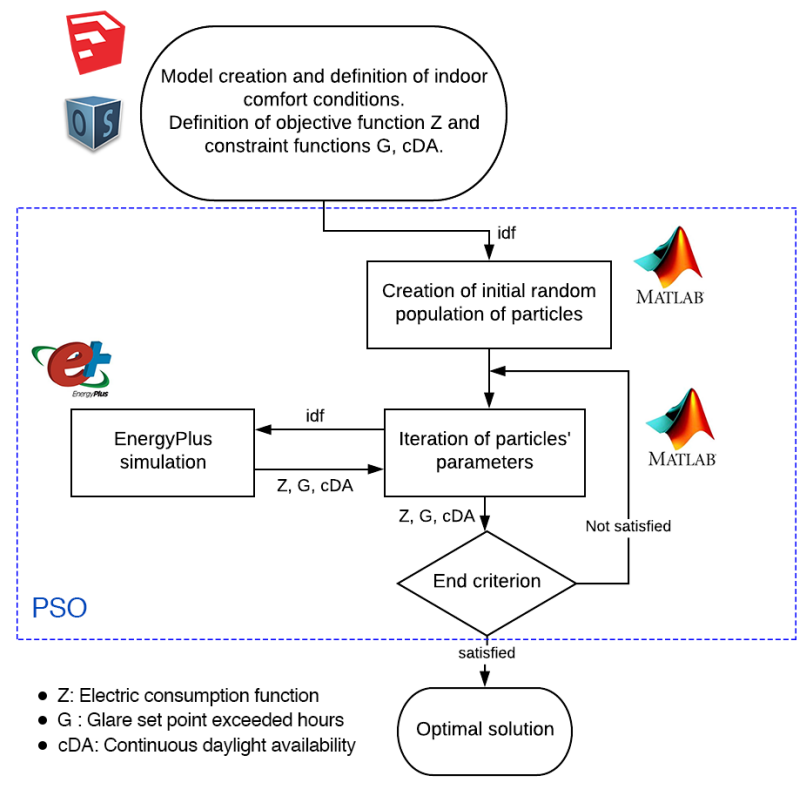

Figure 3: Particle swarm optimization's workflow.

\section{Model set-up}

In order to compare the three different methods in the design of external shading devices, a real office room has been considered, by creating a simplified model of a single thermal zone of an existing building.

\section{Climatic context}

The selected case-study office building is located in Tokyo, Japan (Northern hemisphere). The city, lying in the humid subtropical climate zone, presents moderate/cold winters and hot, very humid summers; the hottest month is August while January is the coldest one. Cooling degree days (CDD), heating degree days (HDD) and yearly irradiation values are shown in Table 1.
Table 1: Tokyo-Climatic data.

\begin{tabular}{|c|c|c|}
\hline HDD & CDD & Yearly solar radiation $\left[\mathbf{k W h} / \mathbf{m}^{\mathbf{2}}\right]$ \\
\hline 2968 & 135 & 1302 \\
\hline
\end{tabular}

\section{Reference room}

The reference room considered (Figure 4) is part of the Institute of Industrial Science (IIS) at The University of Tokyo, with a floor area of $30 \mathrm{~m}^{2}$ and internal height of $2.7 \mathrm{~m}$; it was chosen for the need of a retrofit intervention to improve comfort conditions and aiming at energy saving. A simplified model of the room has been created with SketchUp and OpenStudio, where all the nonexposed façades, which are in the real building adjacent to other office spaces, were considered adiabatic.

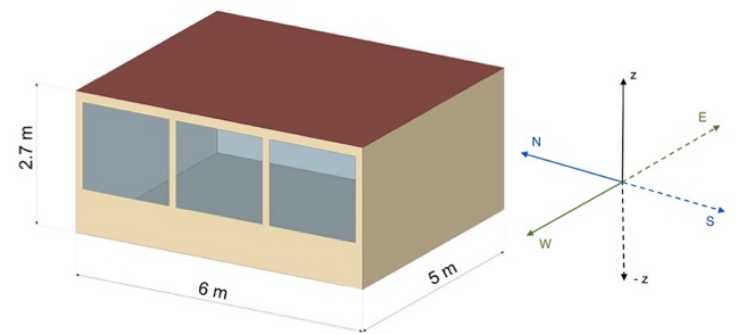

Figure 4: Reference room-Baseline geometric features.

The West facing external wall is characterized by an internal plaster, hollow bricks, insulation material and an external plaster with a 0.3 value of solar absorptance, for an overall $\mathrm{U}$ value of $0.293 \mathrm{~W} / \mathrm{m}^{2} \mathrm{~K}$. The latter wall presents a window-to-wall ratio (WWR) of 55\% and the windows are composed by a standard double glazing filled with air, with a frame percentage of $10 \%$; the $U$ value of $1.5 \mathrm{~W} / \mathrm{m}^{2} \mathrm{~K}$ is representative of the overall window system. Values of solar transmittance $(\mathrm{g})$ and visible transmittance $\left(\tau_{\mathrm{vis}}\right)$ are shown in Table 2 .

Table 2: Proprieties of building components.

\begin{tabular}{|c|c|c|c|}
\hline & $\begin{array}{c}\mathbf{U} \\
{\left[\mathbf{W} / \mathbf{m}^{2} \mathbf{K}\right]}\end{array}$ & $\begin{array}{c}\text { Solar } \\
\text { transmittance, } \\
\mathbf{g}\end{array}$ & $\begin{array}{c}\text { Visible } \\
\text { transmittance, } \\
\boldsymbol{\tau}_{\text {vis }}\end{array}$ \\
\hline External wall & 0.293 & N/A & N/A \\
\hline Window & 1.5 & 0.72 & 0.75 \\
\hline
\end{tabular}

\section{Load profiles}

The profiles related to internal gains, ventilation and heating/cooling modes are the ones corresponding to normal office hours, from 9:00 am until 6:00 pm weekdays, and closed during weekends and holidays. The presence of 4 people is considered in the reference room, which represents the actual average situation. Values of internal gains (Table 3) are suggested from CIBSE regulations, considering an office space outside the city center (CIBSE, 2015). An infiltration of $0.2 \mathrm{ac} / \mathrm{h}$ and a $10 \%$ of the equipment nominal project load have been considered with a continuous profile during the whole year, except for long holidays in which the equipment load goes down to a fraction of $2 \%$ of the nominal value. Indoor comfort set points have been set both in terms of temperature and visual perception (Reinhart, 2013). Thermal set points are reported in Table 4, considering the operative temperature rather than the air temperature. A minimum illuminance of 500 lux on the workplane (at 
sensors location, Figures 5 and 6) has been considered, assuming a dimming profile (Figure 7) for artificial lighting that activates lamps whenever the illuminance is below the defined threshold, with a luminous efficacy of $120 \mathrm{~lm} / \mathrm{W}$. According to CIBSE values and considering 4 workers in the office space, a minimum ventilation rate of $2.7 \mathrm{ac} / \mathrm{h}$ was set to satisfy indoor air quality requirements (CIBSE, 2016).

Table 3: Internal gains.

\begin{tabular}{|c|c|c|c|}
\hline & People & Lighting & Equipment \\
\hline Sensible gains [W/m $]$ & 12 & 10 & 15 \\
\hline
\end{tabular}

Table 4: Indoor set points.

\begin{tabular}{|c|c|}
\hline Set point & Value \\
\hline Cooling $\left[{ }^{\circ} \mathrm{C}\right.$, operative temp] & 26 \\
\hline Heating $\left[{ }^{\circ} \mathrm{C}\right.$, operative temp] & 22 \\
\hline Ventilation for IAQ [ac/h] & 2.7 \\
\hline Minimum illuminance on workplane [lux] & 500 \\
\hline Maximum allowable discomfort glare index [DGI] & 28 \\
\hline
\end{tabular}

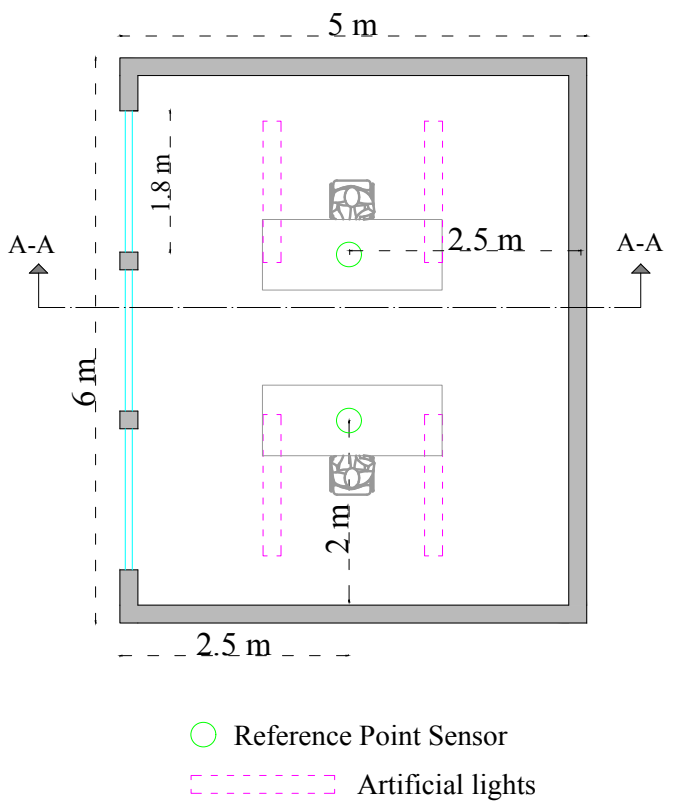

Figure 5: Illuminance sensors position-plan.

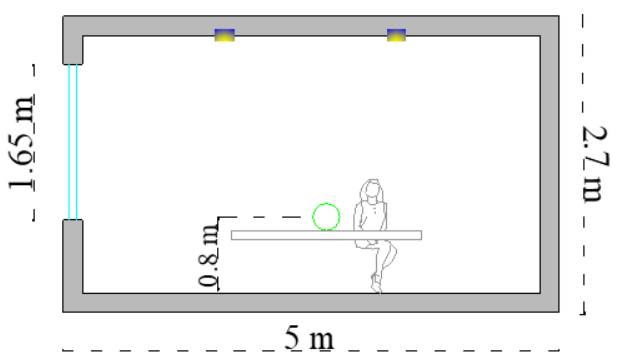

Reference Point Sensor

- Artificial lights

Figure 6: Illuminance sensors position - section.

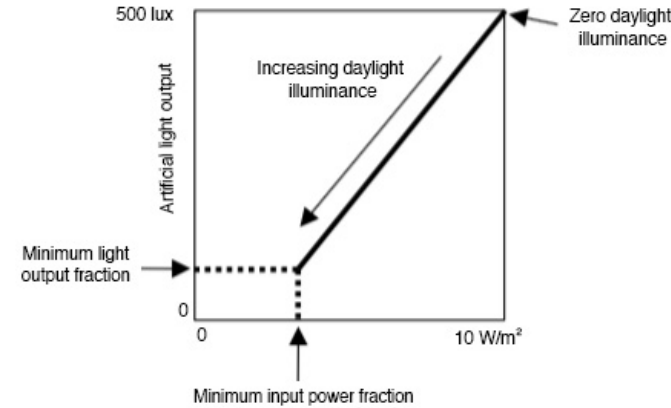

Figure 7: Artificial lighting dimming profile.

\section{Results}

Obtained results are expressed in terms of yearly overall electric consumption for heating, cooling and artificial lighting. In order to sum up the values of lighting and cooling/heating needs, a Seasonal Performance Factor (SPF) of 2.5 for the HVAC system has been assumed; the HVAC system is composed by an electric air-source heat pump coupled with fan-coil units (Miara, 2001). The considered SPF value, which is based on real performances of common heat pumps and represents the ratio between the annual thermal energy supplied to the room and the electricity needed to run the entire plant (Furuno, 2016), is representative of both the coefficient of performance of the heat pump and the efficiencies of the subsystems (distribution, control, emission) and auxiliary systems (circulation pumps, fans etc.). This value is considered as an average value through the year. Thus, it has been possible to convert the thermal energy needs for heating and cooling in terms of electricity needs. Results in terms of glare and continuous daylight availability are instead only used as constraints for the optimization process.

\section{Shading device selection}

For the climate and orientation of the selected case-study, the most performing shading type might be movable external venetian blinds or fixed vertical fins (Lee, 2017); in the present study we decided to analyse the feasibility of the metaheuristic optimization method on the vertical fins (Figure 8), which bring good advantages to the baseline model with lower installation and maintenance costs compared to movable shadings (Aste, 2013).

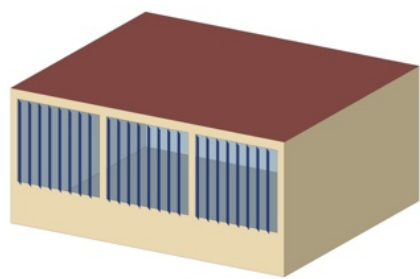

Figure 8: Reference room with vertical fins.

The depth and orientation angle of the vertical fins, during the pre-optimization phase, has been set to $20 \mathrm{~cm}$ and $45^{\circ}$, to find a good compromise between minimizing summer solar load and maximizing winter gains (Givoni, 1998). In addition, this tilt angle represents the average value among the decision range, which varies between $0^{\circ}$ 
(parallel to the window pane) and $90^{\circ}$ (perpendicular to the window pane). The decision range of the fins' depth, instead, fluctuates between $10 \mathrm{~cm}$ and $35 \mathrm{~cm}$. Each window has 8 vertical fins which are arranged at equal distance of $22.5 \mathrm{~cm}$.

According to the performed simulations, the solution with vertical fins is able to reduce the overall electric consumption of $8.8 \mathrm{kWh} / \mathrm{m}^{2}$ per year (Figure 9) and to decrease the number of hours of visual discomfort below the $10 \%$ of the total number of yearly working hours (Figure 10), which is considered as a threshold. The obtained results can be considered the optimal solution according to a traditional design approach.

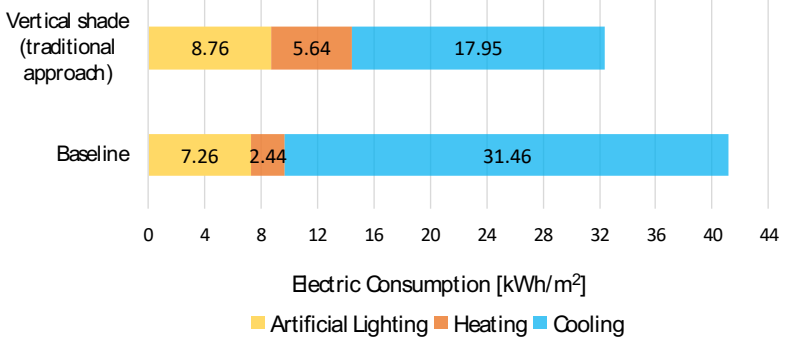

Figure 9: Models comparison - Yearly electric consumption.

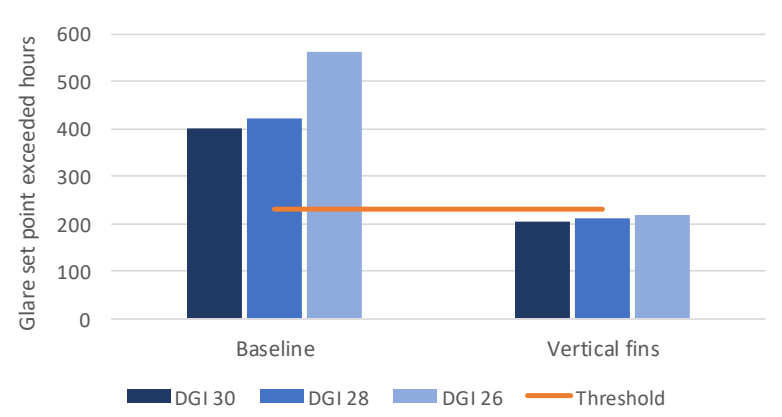

Figure 10: Shading types comparison: glare (yearly).

\section{Optimization results}

The optimization of geometrical properties of the vertical fins (depth, tilt angle) has been studied through a full search and a particle swarm optimization processes in order to evaluate the accuracy and simulation time of both methods (Table 5), also compared to the above-mentioned traditional approach. Optimal geometrical properties found with each method are reported in Table 6.

Table 5: Optimizations comparison.

\begin{tabular}{|c|c|c|}
\hline & $\begin{array}{c}\text { Total electric cons. } \\
{\left[\mathbf{k W h} / \mathbf{m}^{\mathbf{2}}\right]}\end{array}$ & $\begin{array}{c}\text { Total sim. time } \\
{[\mathbf{m i n}]}\end{array}$ \\
\hline Baseline & 41.20 & N/A \\
\hline Trad. approach & 32.35 & N/A \\
\hline Full search & 31.40 & 72 \\
\hline PSO & 31.51 & 36 \\
\hline
\end{tabular}

Table 6: Optimization: final variables' values.

\begin{tabular}{|c|c|c|}
\hline & $\begin{array}{c}\text { Shading depth } \\
{[\mathbf{c m}]}\end{array}$ & $\begin{array}{c}\text { Shading tilt angle } \\
{[\mathbf{d e g}]}\end{array}$ \\
\hline Baseline & N/A & N/A \\
\hline Trad. approach & 20 & 45 \\
\hline Full search & 30 & 46 \\
\hline PSO & 27 & 48 \\
\hline
\end{tabular}

Results of yearly electric consumptions (Figure 11) and visual discomfort (Figure 12) show that the PSO reaches almost identical solutions of the full search, in a lower simulation time.

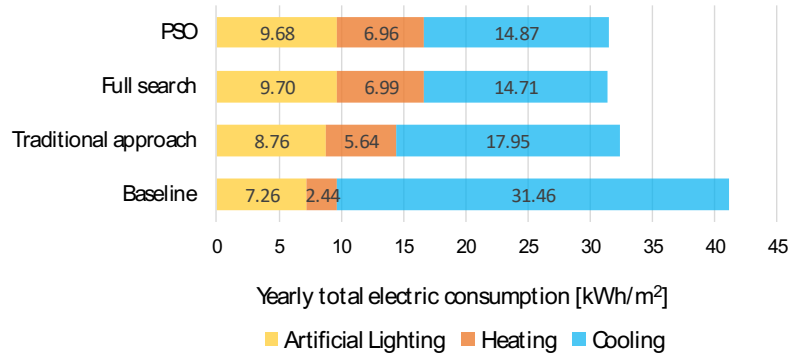

Figure 11: Comparison of electric consumption.

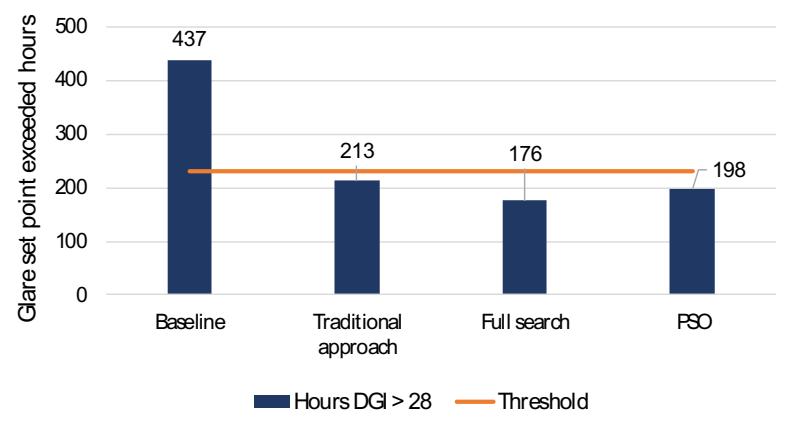

Figure 12: Comparison of glare time (yearly).

\section{Validation of the PSO}

The previous section demonstrated the reliability of PSO algorithm in the optimization of fixed shading devices. This approach can be fundamental whenever the complexity of the problem is too high to perform a full search approach. For this reason, the research has been extended to the glazing properties (visible and solar transmittances), which are optimized in this section simultaneously to the shading geometry in order to understand how different parameters can influence each other, inevitably leading any traditional approach to suboptimal results. Imposed boundaries for the visible transmittance are 0.5 and 0.85 , while the solar transmittance is set between 0.4 and 0.75 , according to average values of commercial products. A maximum gap of 0.3 between the two transmittances has been imposed according to commercial solutions' limits. The results demonstrate that a full search, in a problem slightly more complex than the previous one, would already lead to high time-consuming processes, giving more power to the algorithmic approach. A full search simulation time of $270 \mathrm{~h}$, in fact, has been estimated knowing the total number of possible combinations, but it has not been tested due to its huge amount of required time. This estimation has been computed with a proportion based on the simulation time required for the full search in the previous section. The PSO is instead able to reach a final value of $28.9 \mathrm{kWh} / \mathrm{m}^{2}$ of yearly total electric consumption with a simulation time equal to $4 \mathrm{~h}$; the computation time of a PSO is in fact not proportional to the number of variables, but strictly dependant on the particular problem and parameters, and involves as well random components. Also, it is interesting to notice how the final shape of the 
shading devices (Table 7) is different from the one obtained in the previous paragraph, meaning that the change of glazing properties brought to a different optimal shading geometry, which would not be possibly taken into account with a traditional approach where each parameter is fixed before analysing the following one.

Table 7: Optimization: final variables' values.

\begin{tabular}{|c|c|c|c|c|}
\hline & $\begin{array}{c}\text { Shading } \\
\text { depth [cm] }\end{array}$ & $\begin{array}{c}\text { Shading tilt } \\
\text { angle [deg] }\end{array}$ & g & $\boldsymbol{\tau}_{\text {vis }}$ \\
\hline Baseline & $/$ & $/$ & 0.72 & 0.75 \\
\hline PSO & 22.25 & 50 & 0.55 & 0.85 \\
\hline
\end{tabular}

\section{Further development of the PSO}

In addition to the traditional PSO, two further variations of the latter have been considered and compared in order to understand how this approach could be improved according to the particular case study. Several studies, in fact, showed how the modification of some parameters within the PSO might be really beneficial for particular situations (Tripathi, 2007). Firstly, a Mutated PSO (mPSO) has been adopted, which benefits have already been proved in a different field (Shintaro, 2015). This is based on the addition of a mutation method to the traditional $\mathrm{PSO}$, guaranteeing a certain percentage of uniformly distributed positions of individuals at each iteration, as by Eq. (1-2), where $\mu$ denotes a uniformly distributed number that ranges between the upper and lower boundaries of each decision variable, as previously defined; $\mathrm{X}_{\mathrm{a}, \mathrm{b}, \mathrm{c}, \mathrm{d}}$ denotes instead each element of individual's vector. A constant mutation rate (mrate) of 5\% has been set, which implies a $5 \%$ of probability, at each iteration, that the parameters of a particle assume random values, within the boundary ranges.

$$
\begin{array}{ll}
- & X_{a, b, c, d, e}=\mu \text { if rand }<\text { mrate } \\
\text { - } \quad & X_{a, b, c, d, e}=X_{a, b, c, d, e} \text { if rand }>\text { mrate }
\end{array}
$$

Table 8 shows results reached with this mutation, which however leads to a different drawback, in this particular case: due to the fact that the end criterion has been imposed on the convergence of the particles, the mutation rate added by the m-PSO at each iteration causes the impossibility for the particles to converge all together and thus the impossibility to end the simulation according to the previously defined end criterion. This obliged us to change the end criterion by assigning a maximum number of iterations to the analysis, which might create doubts about the correct number of maximum iterations or bring to unwanted additional simulation time. For this reason, a third version of the PSO, a damped mutated PSO (damp$\mathrm{m}$-PSO) has been developed, which adds to the mutation rate of the m-PSO a damping factor $(\psi=0.89)$, decreasing the mutation rate at each iteration. In this way it is possible to obtain a higher randomness in the beginning of the search, which decreases at each iteration until bringing the mutation rate to a nearly zero value, allowing the particles to converge similarly to the traditional PSO. Furthermore, this method allowed to increase the mutation rate of the $\mathrm{m}$-PSO from $5 \%$ to $8 \%$, decreasing even more the risk for the particles to be stuck in local optima in the beginning of the search. This improvement, however, might not be ideal in other studies where the risk of local optima is present even in the last iterations, thus a constant mutation rate of the m-PSO might be fundamental.

Table 8: Performance comparison of different PSOs.

\begin{tabular}{|c|c|c|}
\hline & $\begin{array}{c}\text { Total electric cons. } \\
{\left[\mathbf{k W h} / \mathbf{m}^{2}\right]}\end{array}$ & $\begin{array}{c}\text { Total sim. time } \\
{[\mathbf{h}]}\end{array}$ \\
\hline PSO & 28.9 & 4 \\
\hline m-PSO & 28.21 & $4^{*}$ \\
\hline damp-m-PSO & 28.21 & 4 \\
\hline
\end{tabular}

*maximum number of iterations imposed (15)

\section{Population number and starting distribution}

The previously analysed particle swarm optimizations have been conducted with a starting population of 100 particles; this number has been chosen after many trials which demonstrated that a lower number would lead to non-optimal results while a higher number would only increase the simulation time without bringing any advantage to the final result, as shown in Figure 13. Different studies will need different population sizes in order to find the optimal solution; however, experience can play a good role in understanding which is the proper size, according to the number of variables of the problem and the width of the variables' range. Trial and errorbased approach can be considered the safest way to avoid mistakes related to wrong assumptions. Results show how a number of particles below 100, in this particular case, would lead to solutions which are quite far from the optimal one, although obviously leading to good timesavings (Figure 14). Sometimes, when the designer doesn't require a very high accuracy in the final result (which might be the case of some passive strategies where the final solution will however be approximated due to limits in materials' production), the time-saving related to lower population number might be very interesting.

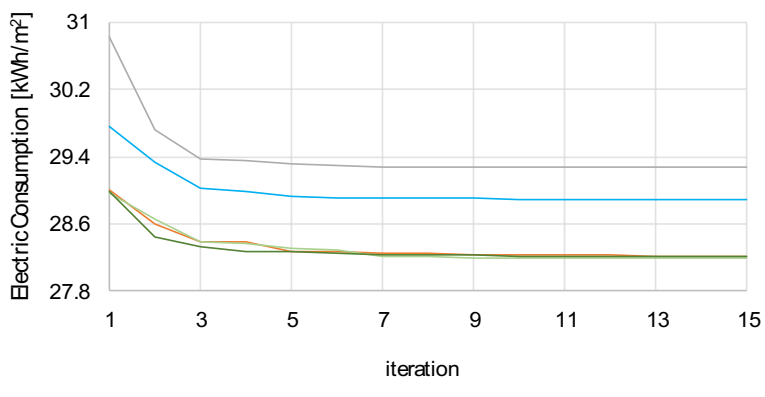

nPop: $50-$ nPop: $75-$ nPop: $100-$ nPop: $125-$ nPop: 150

Figure 13: Population comparison: electric consumption.

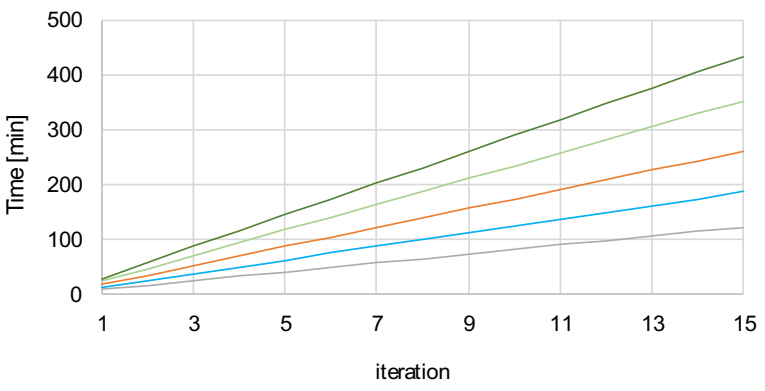

nPop: $50-$ nPop: $75-$ nPop: $100-$ nPop: $125-$ nPop: 150

Figure 14: Population comparison: simulation time. 
In order to find a way to make more realistic the possibility of lowering the population number when seeking for time saving while trying to worsen as less as possible the accuracy of the results, we studied a new way of distributing the first generation of particles. The traditional particle swarm optimization is characterized by a random first generation of particles, which leads to bad results with low population numbers due to the fact that wide areas in the search space are not covered at all. The same analysis on population number previously performed has now been done modifying the starting random population with a Latin hypercube sampling (LHS) distribution, i.e. a near-random distribution which represents a multidimensional generalization of the Latin square concept (Helton, 2003), with a number of dimensions equal to the number of variables of the problem. This solution does not bring any advantage when the number of particles is high enough to find the optimal result (thus bringing to the same result previously found) but gives good advantages when the population number is lower than the minimum needed (Figure 15).

The results reached with population numbers of 50 and 75 particles are in fact much closer to the real optimal solution rather than the ones obtained with the same number of particles but with a random generation. The computation time (Figure 16) is exactly the same of the previous method, thus showing how this different starting distribution does not present any time-related drawback.

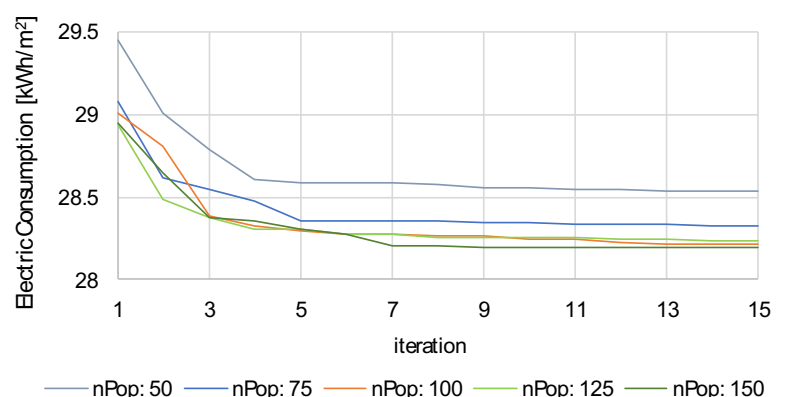

Figure 15: Population comparison (LHS): electric consumption.

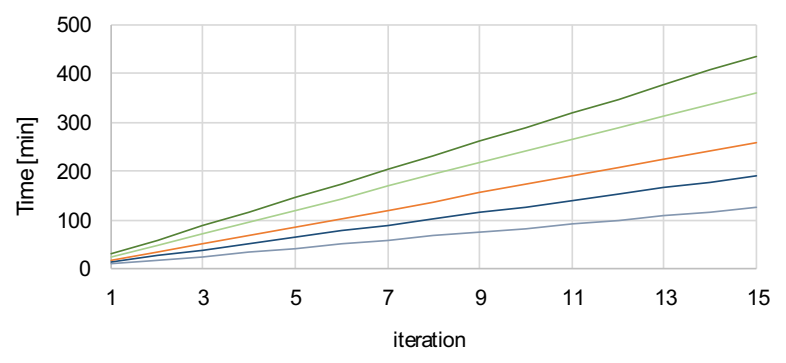

- nPop: $50-n$ nPop: $75-$ nPop: $100-$ nPop: $125-n$ nPop: 150

Figure 16: Population comparison (LHS): electric consumption.

\section{Conclusions}

This paper focused on the analysis of the feasibility of a metaheuristic optimization approach in the design of external shading devices, assessing the energy and comfort performances in the application on an office building.
The metaheuristic approach was found reliable also for the design of passive strategies aimed at the reduction of heating, cooling and daylighting consumption and the improvement of indoor environmental conditions, especially in terms of simulation-time savings when compared to traditional approaches. It was shown how an in-depth study of each parameter of the particle swarm optimization could bring to higher accuracy in the final solution. Eventually, the use of a Latin hypercube sampling distribution can help in reducing the simulation time when high accuracy in the final solution is not needed. The other novelty introduced, that is the integration of Matlab and EnergyPlus without the use of any middleware tool, allows this method to be used in any kind of passive strategy optimization, considering that all the geometries, materials and building properties are present in the idf file used by EnergyPlus for energy simulations. Lastly, any constraint function can be considered in the optimization process, giving the designer complete freedom of choice on optimization parameters and criteria, which is fundamental in building design field, where standard hypotheses/parameters might lead to wrong conclusions or huge simulation efforts.

\section{Nomenclature}

\begin{tabular}{|ll|}
\hline $\mathrm{CO}_{2}$ & Carbon dioxide \\
$\mathrm{GB}$ & Green building \\
$\mathrm{PSO}$ & Particle swarm optimization \\
$\mathrm{cDA}$ & Continuous daylight autonomy [\%] \\
$\mathrm{DGI}$ & Discomfort glare index [-] \\
$\mathrm{U}$ & Thermal transmittance [W/m $\left./ \mathrm{m}^{2} \mathrm{~K}\right]$ \\
$\mathrm{WWR}$ & Window to wall ratio [\%] \\
$\mathrm{G}$ & Solar transmittance [-] \\
$\tau_{\text {vis }}$ & Visible transmittance [-] \\
ac/h & Air changes per hour [vol/h] \\
$\mathrm{SPF}$ & Seasonal performance factor [-] \\
$\mathrm{m}-\mathrm{PSO}$ & Mutated PSO \\
$\mathrm{mrate}$ & Mutation rate [\%] \\
damp-m- & Damped Mutated PSO \\
$\mathrm{PSO}$ & \\
$\psi$ & Damping factor [-] \\
LHS & Latin hypercube sampling \\
idf & Instrument definition file \\
\hline
\end{tabular}

\section{References}

Aste, N., Adhikari, R. S. \& Del Pero, C. (2012). An algorithm for designing dynamic solar shading system. Energy Procedia 30, 1079-1089.

Aste, N., Buzzetti, M., Del Pero, C. \& Leonforte, F. (2018). Glazing's techno-economic performance: A comparison of window features in office buildings in different climates. Energy and Buildings 159, 123135.

Banks, A., Vincent, J., Anyakoha, C. (2008). A review of particle swarm optimization. Part II: hybridisation, combinatorial, multicriteria and constrained optimization, and indicative applications. Natural Computing 7(1), 109-124. 
Bellia, L., De falco, F. \& Minichiello, F. (2013). Effects of solar shading devices on energy requirements of standalone office buildings for Italian climates. Applied Thermal Engineering 54(1), 190-201.

Carlucci, S., Causone, F., De Rosa F. \& Pagliano, L. (2015). A review of indices for assessing visual comfort with a view to their use in optimization processes to support building integrated design. Renewable and Sustainable Energy reviews 47, 10161033.

Chan, Y. \& Tzempelikos, A. (2013). Efficient venetian blind control strategies considering daylight utilization and glare protection. Solar Energy 98(C), 241-254.

Chantrelle, F., P., Lahmidi, H., Keilholz, W., El Mankibi, M., Michel, P. (2011). Development of a multicriteria tool for optimizing the renovation of buildings. Applied Energy 88(4), 1386-1394.

Decreto del Presidente della Repubblica (2009). Regolamento di attuazione dell'articolo 4, comma 1, del decreto legislativo 19 Agosto 2005, sul rendimento energetico in edilizia.

EU Hub (2016). European commission's science and knowledge service. Energy efficiency: buildings.

Furuno, S., Okushima, L. \& Sase, S. (2016). Comparison of coefficient of performance (COP) between an underground water source heat pump system and an air source heat pump system for greenhouse heating in cold and snowy areas in Japan. Journal of Agricultural Meteorology 72(3-4), 173-177.

Givoni, B. (1998). Climate considerations in Building and Urban Design. Wiley (US).

Grynning, S., Time, B. \& Matusiak, B. (2014). Solar shading control strategies in cold climates - Heating, cooling demand and daylight availability in office spaces. Solar Energy 107, 182-194.

Helton, J. C. \& Davis, F. J. (2003). Latin hypercube sampling and the propagation of uncertainty in analyses of complex systems. Reliability Engineering and Sistem Safety 81(1), 23-69.

Lee, K. S., Han, K. J. \& Lee, J. W. (2017). The impact of shading type and azimuth orientation on the daylighting in a classroom. Energies 10(5).

Miara, M., Gunther, D., Kramer, T., Oltersdorf, T. \& Wapler, J. (2011). Heat pump efficiency: Analysis and evaluation of heat pump efficiency in real life conditions. Fraunhofer. Munich (DE).

Mohsini, R. A. \& Davidson, C. H. (2006). Determinants of performance in the traditional building process. Construction Management and Economics 10(4), 343-359.
Morrissey, J., Moore, T. \& Horne, R. E. (2011). Affordable passive solar design in a temperate climate: An experiment in residential building orientation. Renewable Energy 36(2), 568-577.

Reinhart, C. \& LoVerso, VRM. (2010). A rules of thumb based design sequence for diffuse daylight. Lighting Research and Technology 42(1), 7-31.

Reinhart, C., Mardaljevic, J. \& Rogers, Z. (2013). Dynamic daylight performance metrics for sustainable building design. The Journal of the Illuminating Engineering Society 3(1), 7-31.

Shintaro, I. \& Ooka, R. (2015). Metaheuristic optimization methods for a comprehensive operating schedule of battery, thermal energy storage, and heat source in a building energy system. Applied energy 151, 192-205.

The Chartered Institution of Building Services Engineers (2016). CIBSE Guide B2: Ventilation and indoor air quality classification -- Table 4.1.

The Chartered Institution of Building Services Engineers (2015). CIBSE Guide A: Benchmark for internal gains -- Table 6.1 and Table 6.2.

Trelea, I. C. (2003). The particle swarm optimization algorithm: convergence analysis and parameter selection.Information Processing Letters 85, 317-325.

Tripathi, P. K., Bandyopadhyay, S., Pal, S. K. (2007). Multi-Objective particle swarm optimization with time variant inertia and acceleration coefficients. Information Sciences 177(22), 5033-5049.

Van Den Bergh, F. \& Engelbrecht, A.P. (2005). A study of particle swarm optimization particle trajectories. Information Sciences 176(8), 937-971.

Vischer, J.C. (2011). Towards an environmental psychology of workspace: How people are affected by environments for work. Architectural science review 51(2), 97-108.

Yang, X. (2010). Nature-Inspired metaheuristic algorithms, $2^{\text {nd }}$ ed. Luniver Press. London (UK)

Yener, A.K. (1998). A method of obtaining visual comfort using fixed devices in rooms. Building and Environment 34(3), 285-291.

Wetter, M. (2011). Co-simulation of building energy and control systems with the Building Control Virtual Test Bed. Journal of Building Performance Simulation 4(3), 185-203.

Znouda, E., Ghrab-Morcos, N. \& Hadj-Alouane, A. (2007). Optimization of mediterranean building using genetic algorithms. Energy and Buildings 39, 148-15. 